\title{
Combining efforts to solve Brazil's oral health problem
}

Kátia Regina H. C. Dias

President of the $\mathrm{SBPqO}$ n October 2007 the Johnson \& Johnson Company (Johnson \& Johnson do Brasil Indústria e Comércio para Saúde Ltda.) hosted the first meeting of the Brazilian Oral Health Panel in the city of São Paulo, a meeting of renowned professionals in dentistry, including some partners of long-term projects, such as the "Boca Limpa, Saúde Total" (Clean Mouth, Total Health) and the "ASBLA - Atualização em Saúde Bucal Latino-Americana" (Update on Latin American Oral Health).

The aim of the meeting was to create a panel to discuss oral health in Brazil. The group was formed by representatives from different regions in the country and of various specialties, such as Restorative Dentistry, Epidemiology, Pediatric Dentistry, Periodontics and Prosthodontics. The idea was to discuss dentistry-related problems that affect the Brazilian population, mainly caries and periodontal diseases. In addition, the discussion addressed causes and treatments, and determined the best way to spread the message of prevention in public health.

The first meeting of the Brazilian Oral Health Panel addressed epidemiological data from the survey developed by the Brazilian Ministry of Health and published in 2003. The panel noted that Brazil has advanced in the prevention of caries in children, in the past decade; however, the situation among adolescents, adults and the elderly is still one of the worst in the world. Even among children, gingival problems and difficulties in obtaining dental care persist. Striving to change this framework, the Federal Government established a National Policy on Oral Health, through the "Brasil Sorridente" (Smiling Brazil) Program, which combines several actions in oral health, geared to people of all ages.

The group concluded that, despite the efforts of the Federal Government and the creation of programs addressing oral health and culminating in the reduction of the DMFT in some cities, the situation remains alarming, since much of the Brazilian population still has no access to preventive care or even dental treatment. Something must be done. Shortand long-term actions need to be implemented. How can the group contribute to solving the problem?

With the support of Johnson \& Johnson (Johnson \& Johnson do Brasil Indústria e Comércio para Saúde Ltda.), all the participants of the group have volunteered to develop and publish proposals for short- and long-term actions, aiming at reducing the prevalence of caries and periodontal disease, and thus impacting public health favorably.

The results of the literature, the clinical and the laboratory reviews performed by the group are now being released in a special issue of BOR sponsored by Johnson \& Johnson, strictly observing all the peer-review publishing procedures. 
This special issue presents five review articles:

- Oral Health in Brazil - Part I: Public Oral Health Policies

- Oral Health in Brazil - Part II: Dental Specialty Centers (CEOs)

- Reviewed evidence about the safety of the daily use of alcohol-based mouthrinses

- Association between periodontal diseases and systemic diseases
- Halitosis: a review of associated factors and therapeutic approach

The solution to our problems cannot be expected to come from the government! Something needs to be done imperatively. Teachers, researchers and opinion leaders on one hand, and an insightful multinational company on the other hand, share a commitment to seeking solutions to the oral health problems affecting Brazil. It's a partnership that is bound to succeed! 